JURNAL ILMIAH TEKNIK MESIN, ELEKTRO DAN KOMPUTER

Halaman Jurnal: http://ejurnal.stie-trianandra.ac.id/index.php/juritek

Halaman UTAMA Jurnal : http://ejurnal.stie-trianandra.ac.id/index.php

\title{
RANCANG BANGUN PROTOTYPE DISPLAY ANTRIAN PELANGGAN DENGAN PENGGUNAAN TEKS DAN SUARA BERBASIS JARINGAN INTRANET
}

\author{
Dewi Amirakhima , Anggarda Putera Yunizar \\ Sekolah Tinggi Teknik Mangkubumi, Surakarta
}

\begin{abstract}
ABSTRAK
The development of information technology in various fields, one of which is in the field of queuing systems. That we know about the queuing system which is so tedious because of the long process of queuing. Therefore, the number of customer queues at several banks so that customers cannot relax to carry out transactions at the bank is a problem that is often encountered, as well as what happened at PT. BPR SARIBUMI Bank Godong Branch, which still uses a manual system. To overcome this problem, a queue display is used that uses text and voice displays and prints the queue serial number so that customers no longer need to queue conventionally.

With this queuing system, the queue counter clerk, cashier or teller will have no difficulty in determining the first person to be served in the queue. This is a solution, but the display of the queue display uses electronic equipment that performs a counter so that the possibility of damage to the device exists. In making this final project the author uses Microsoft Visual Basic 6.0 software and MySQL database.
\end{abstract}

Keywords: queue display, network, serial number display and client - server

\begin{abstract}
Abstrak
Semakin berkembangnya teknologi informasi diberbagai bidang yaitu salah satunya dibidang sistem antrian. Bahwa kita tahu tentang sistem antrian yang begitu membosankan karena lamanya proses untuk mengantri. Maka dari itu banyaknya antrian nasabah di beberapa bank sehingga nasabah tidak dapat santai untuk melaksanakan transaksi di bank merupakan masalah yang sering dijumpai, begitu juga yang terjadi di Bank PT.BPR SARIBUMI Cabang Godong ini yang masih menggunakan sistem manual. Untuk mengatasi permasalahan tersebut digunakan display antrian yang menggunakan tampilan teks dan suara dan cetak nomor urut antrian sehingga nasabah tidak perlu lagi mengantri secara konvensional.

Dengan adanya sistem antrian ini membuat petugas loket antrian, kasir atau teller tidak akan kesulitan dalam menentukan orang pertama yang akan dilayani dalam antrian. Hal tersebut merupakan sebuah solusi tetapi tampilan display antrian menggunakan peralatan elektronik yang melakukan counter sehingga kemungkinan terjadi kerusakan pada alat tersebut ada. Dalam pembuatan Tugas Akhir ini penulis menggunakan software Microsoft Visual Basic 6.0 dan Database MySQL.
\end{abstract}

Kata kunci : display antrian, jaringan, display nomor urut dan client - server

\section{Pendahuluan}

Teknologi jaman sekarang mengalami perkembangan sangat pesat, berkembang dari masa ke masa seiring dengan meningkatnya kemampuan dan kebutuhan hidup manusia. Teknologi yang mempunyai peran penting dalam kehidupan manusia adalah komputer. Peran komputer terbukti banyak dibutuhkan dan digunakan sebagai alat bantu dalam mengolah data informasi dan mengendalikan berbagai peralatan yang digunakan untuk membantu manusia dalam menjalankan tugasnya sehari - hari. Komputer juga telah banyak sekali membantu menyelesaikan dan mengatasi masalah dari yang paling mudah hingga yang paling rumit. Hingga komputer tidak bisa dipisahkan dari aktivitas manusia dari setiap pekerjaannya.

Semakin meningkatnya penggunaan teknologi informasi diberbagai bidang sehingga menjadi acuan penulis untuk mengatasi permasalahan tentang antrian yang ada pada tiap - tiap instansi atau lembaga pemerintah dan pusat - pusat layanan pelanggan maupun masyarakat. Perlu diketahui bahwa untuk antri

Received September 24, 2021; Revised Oktober 2, 2021; Accepted Oktober 22, 2021 
*Dewi Amirakhima dkk / Jurnal IImiah Teknik Mesin, Elektro dan Komputer Vol 1. No. 3 (2021) 34 - 44

pada loket layanan dan juga transaksi lewat kasir atau petugas loket, harus siap antri berdiri secara berurut selama bermenit - menit lamanya, bahkan jika banyak pelanggan yang datang menyebabkan antrian yang terlalu banyak menyebabkan pelanggan menjadi merasa tidak nyaman dalam melakukan antrian. Tentu saja hal ini kurang menyenangkan dan cenderung memboroskan waktu. Di sebagian pusat layanan masyarakat seperti Bank, Koperasi, Jasa Pelayanan yang lain sudah menerapkan teknologi antrian dengan memberikan nomor urut antrian dan tampilan display text nomor urut, sehingga antrian secara berdiri berurut yang dulunya berbasis antrian satu persatu untuk menunggu antrian mulai dihilangkan sehingga pelanggan dapat menunggu antrian secara nyaman dan tidak perlu melakukan antrian salin menyerobot ingin cepat dilayani. Seperti yang penulis analisa dan perhatikan di Kantor Cabang PT. BPR Saribumi Cabang Godong yang beralamatkan di Jalan Jenderal Sudirman 5 Kecamatan Godong Kabupaten Grobogan ini masih menggunakan proses antriannya dengan manual atau masih menggunakan jasa manusia. Hal ini dapat memicu terjadinya kesalahan manusia (Human Error) dan mengakibatkan munculnya antrian yang berkepanjangan dan dapat membuat pelanggan menjadi bosan akibat lamanya proses antrian

\section{Landasan Teori}

Antrian (queueing) adalah kejadian yang sering dijumpai dalam kehidupan sehari - hari. Menunggu didepan loket untuk mendapatkan sebuah tiket atau nomor antrian. Menunggu itu memakan waktu, sementara waktu merupakan sumber daya yang berharga. Antrian timbul disebabkan oleh kebutuhan akan layanan melebihi kemampuan (kapasitas) pelayanan atau fasilitas layanan, sehingga pengguna fasilitas yang tiba tidak bisa segera mendapat layanan disebabkan kesibukan layanan. Pada banyak hal, tambahan fasilitas pelayanan dapat diberikan untuk mengurangi antrian atau untuk mencegah timbulnya antrian. Akan tetapi biaya karena memberikan pelayanan tambahan, akan menimbulkan pengurangan keuntungan mungkin sampai dibawah tingkat yang dapat diterima. Sebaliknya, sering timbulnya antrian yang panjang akan mengakibatkan hilangnya pelanggan / nasabah.

Teori Antrian (Queuering Theory) merupakan studi matematika dari antrian atau kejadian garis tunggu (Waiting Lines). Teori antrian ini pertama kali diketemukan dan dikembangkan oleh ahli matematika dan insinyur berkebangsaan Denmark yang bernama A.K Erlang pada tahun 1909. Dia mengembangkan model antrian untuk menentukan jumlah yang optimal dari fasilitas telephone switching yang digunakan untuk melayani permintaan yang ada. Penggunaan model ini makin meluas tepatnya mulai sejak akhir perang dunia ke - II. Sampai saat ini, waiting line theory mempunyai aplikasi yang luas untuk alat operasi perusahaan atau manajemen. Persoalan yang dapat diselesaikan dengan teori antrian adalah meliputi bagaimana perusahaan dapat menentukan waktu dan fasilitas yang sebaik - baiknya agar dapat melayani konsumen atau langganan dengan efisien. Di dalam hal ini tentu saja diperhitungkan antara ekstra biaya yang dikeluarkan perusahaan untuk menambah fasilitas service baru dengan kerugian - kerugian konsumen karena harus menunggu apabila tidak diadakan penambahan fasilitas service yang baru.

Dengan demikian, yang menjadi tujuan utama teori antrian ini adalah mencapai keseimbangan antara ongkos pelayanan dengan ongkos yang disebabkan oleh adanya waktu menunggu (Pangestu Subagyo, 2000, 264). Dengan kata lain tujuan dasar teori antrian adalah untuk meminimumkan total dua biaya, yaitu biaya langsung penyediaan fasilitas pelayanan dan biaya tidak langsung yang timbul karena para konsumen menunggu untuk dilayani.

Teori antrian sendiri tidak langsung memecahkan persoalan - persoalan diatas. Walaupun begitu, teori antrian menyumbangkan informasi penting yang diperlukan untuk membuat keputusan dengan cara memprediksi beberapa karakteristik dari baris penungguan. Model antrian yang akan dibahas merupakan peralatan penting untuk sistem pengelolaan yang menguntungkan dengan menghilangkan antrian.

Dengan demikian teori antrian yakni suatu garis tunggu dari pelanggan yang memerlukan layanan dari sistem yang ada. Dalam sektor jasa, bagi sebagian orang antri merupakan hal yang paling membosankan dan sebagai akibatnya terlalu lama antri, maka akan menyebabkan pelanggan kabur atau meninggalkan tempat antrian. Hal ini merupakan suatu kerugian bagi tempat pelayanan jasa tersebut.

Untuk mempertahankan pelanggan, sebuah tempat pelayanan jasa selalu berusaha untuk memberikan pelayanan yang terbaik dan memuaskan. Pelayanan yang terbaik tersebut diantaranya adalah memberikan pelayanan yang cepat, tepat, ramah dan juga efisien. Sehingga pelanggan tidak dibiarkan terlalu lama untuk menunggu (mengantri) dan merasa bosan. Namun demikian, dampak pemberian layanan yang cepat ini akan menimbulkan biaya bagi tempat pelayanan jasa itu sendiri, karena harus menambah fasilitas layanan. Oleh karena itu, layanan yang cepat, tepat, ramah dan juga efisien akan sangat membantu untuk mempertahankan pelanggan, yang dalam jangka panjang tentu saja akan meningkatkan keuntungan bagi tempat pelayanan jasa itu sendiri.

Sistem antrian adalah suatu proses dimana pelanggan akan diarahkan oleh sebuah sistem yang mengatur suatu aturan antrian. Pelanggan yang tiba biasanya bersifat tidak tetap untuk memperoleh

RANCANG BANGUN PROTOTYPE DISPLAY ANTRIAN PELANGGAN DENGAN PENGGUNAAN TEKS DAN SUARA BERBASI JARINGAN INTRANET 
*Dewi Amirakhima dkk / Jurnal IImiah Teknik Mesin, Elektro dan Komputer Vol 1. No. 3 (2021) 34 - 44

pelayanan. Dikarenakan pelanggan harus menunggu untuk sebuah antrian, maka mereka harus membentuk sebuah antrian hingga tiba waktu pelanggan. Ada tiga komponen dasar dalam sistem antrian yaitu :

a. Kedatangan

Karakteristik dari populasi yang akan dilayani (calling population) dapat dilihat menurut ukurannya, pola kedatangan, serta perilaku dari populasi yang akan dilayani. Menurut ukurannya, populasi yang akan dilayani bisa terbatas (finite) bisa juga tidak terbatas (infinite). Sebagai contoh jumlah mahasiswa yang antri untuk registrasi di sebuah perguruan tinggi sudah diketahui jumlahnya (finite), sedangkan jumlah nasabah bank yang antri untuk setor, menarik tabungan, maupun membuka rekening baru, bisa tak terbatas (infinite). Pola kedatangan bisa teratur, bisa juga acak (random). Kedatangan yang teratur sering dijumpai pada proses pembuatan / pengemasan produk yang sudah distandardisasi.

Pada proses semacam ini, kedatangan produk untuk diproses pada bagian selanjutnya biasanya sudah ditentukan waktunya, misalnya setiap 30 detik. Sedangkan pola kedatangan yang sifatnya acak (random), banyak dijumpai misalnya kedatangan nasabah di bank. Pola kedatangan yang sifatnya acak dapat digambarkan dengan distribusi statistik dan dapat ditentukan dua cara yaitu kedatangan per satuan waktu dan distribusi waktu antar kedatangan.

b. Antri

Timbulnya antrian terutama tergantung dari sifat kedatangan dan proses pelayanan. Penentu antrian lain yang penting adalah disiplin antrian. Displin antrian adalah aturan keputusan yang menjelaskan cara melayani pengantri.

Inti dari analisa antrian adalah antri itu sendiri. Timbulnya antrian terutama tergantung dari sifat kedatangan dan proses pelayanan. Jika tak ada antrian berarti terdapat pelayan yang menganggur atau kelebihan fasilitas pelayanan (Mulyono, 1991).

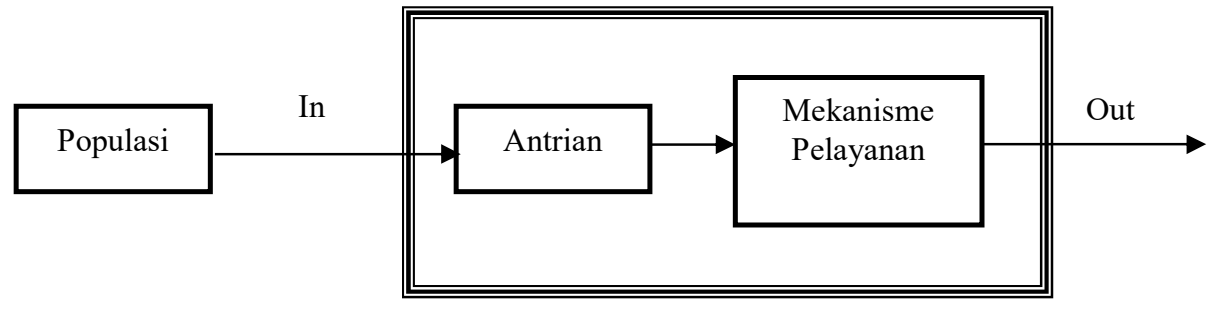

Gambar 1 Proses Mekanisme Antrian

Menurut (Supranto, 1987) penentu antrian lain yang penting adalah disiplin antri. Disiplin antri adalah aturan keputusan yang menjelaskan cara melayani pengantri. Menurut Siagian (1987), ada 5 bentuk disiplin pelayanan yang biasa digunakan, yaitu :

a) First-Come First-Served (FCFS) atau First-In First-Out (FIFO) artinya, lebih dulu datang (sampai), lebih dulu dilayani (keluar). Misalnya, antrian pada loket pembelian tiket bioskop.

b) Last-Come First-Served (LCFS) atau Last-In First-Out (LIFO) artinya, yang tiba terakhir yang lebih dulu keluar. Misalnya, sistem antrian dalam elevator untuk lantai yang sama.

c) Service In Random Order (SIRO) artinya, panggilan didasarkan pada peluang secara random, tidak soal siapa yang lebih dulu tiba.

d) Priority Service (PS) artinya, prioritas pelayanan diberikan kepada pelanggan yang mempunyai prioritas lebih tinggi dibandingkan dengan pelanggan yang mempunyai prioritas lebih rendah, meskipun yang terakhir ini kemungkinan sudah lebih dahulu tiba dalam garis tunggu. Kejadian seperti ini kemungkinan disebabkan oleh beberapa hal, misalnya seseorang yang dalam keadaan penyakit lebih berat dibanding dengan orang lain dalam suatu tempat praktik dokter.

Dalam hal di atas telah dinyatakan bahwa entitas yang berada dalam garis tunggu tetap tinggal di sana sampai dilayani. Hal ini bisa saja tidak terjadi. Misalnya, seorang pembeli bisa menjadi tidak sabar menunggu antrian dan meninggalkan antrian. Untuk entitas yang meninggalkan antrian sebelum dilayani digunakan istilah pengingkaran (reneging). Pengingkaran dapat bergantung pada panjang garis tunggu atau lama waktu tunggu. Istilah penolakan (balking) dipakai untuk menjelaskan entitas yang menolak untuk bergabung dalam garis tunggu (Setiawan, 1991).

1. Struktur Antrian

Ada 4 model struktur antrian dasar yang umum terjadi dalam seluruh sistem antrian :

JURNAL ILMIAH TEKNIK MESIN, ELEKTRO DAN KOMPUTER Vol.1, No.3, November 2021, pp. 34 - 44 
a. Single Channel - Single Phase

Single Channel berarti hanya ada satu jalur yang memasuki sistem pelayanan atau ada satu fasilitas pelayanan. Single Phase berarti hanya ada satu pelayanan.

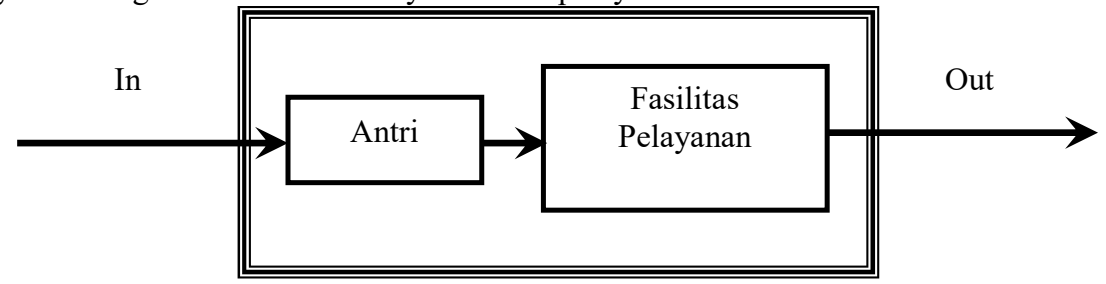

Gambar 2 Model Single Channel - Single Phase

\section{b. Single Channel - Multi Phase}

Istilah Multi Phase menunjukkan ada dua atau lebih pelayanan yang dilaksanakan secara berurutan (dalam phase - phase). Sebagai contoh : pencucian mobil.

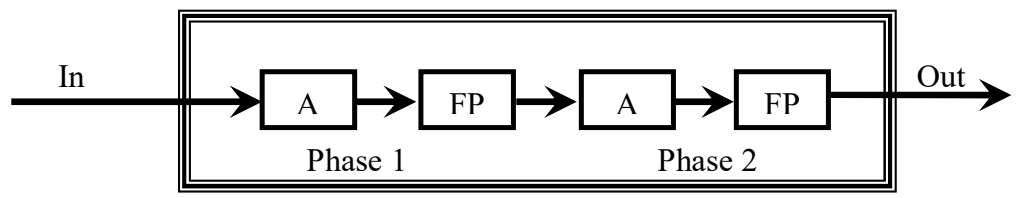

Keterangan :

Gambar 3 Model Single Channel - Multi Phase

$$
\begin{array}{ll}
\mathrm{A} & =\text { Antrian } \\
\mathrm{FP} & =\text { Fasilitas Pelayanan }
\end{array}
$$

c. Multi Channel - Single Phase

Sistem Multi Channel - Single Phase terjadi kapan saja di mana ada dua atau lebih fasilitas pelayanan dialiri oleh antrian tunggal, sebagai contoh model ini adalah antrian pada teller sebuah bank.

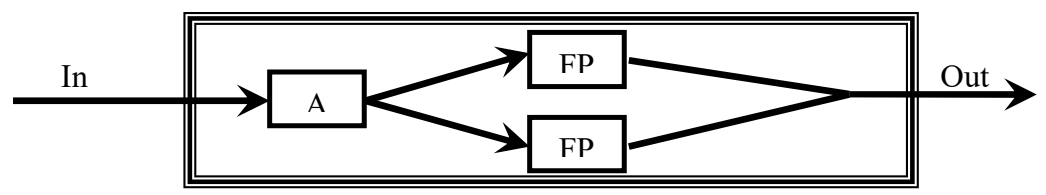

Keterangan :

$$
\begin{array}{ll}
\mathrm{A} & =\text { Antrian } \\
\mathrm{FP} & =\text { Fasilitas Pelayanan }
\end{array}
$$

d. Multi Channel - Multi Phase

Sistem Multi Channel - Multi Phase. Setiap sistem - sistem ini mempunyai beberapa fasilitas pelayanan pada setiap tahapnya. Sebagai contoh, herregistrasi para mahasiswa di universitas, pelayanan kepada pasien di rumah sakit mulai dari pendaftaran, diagnosa, penyembuhan sampai pembayaran.

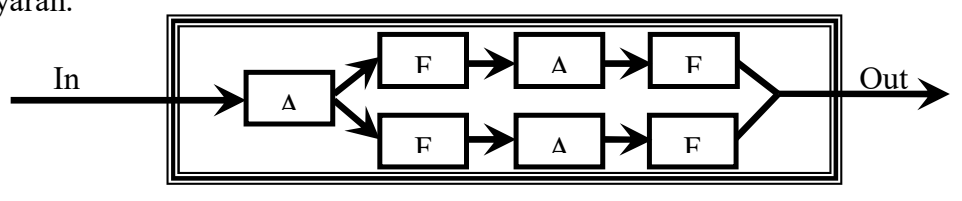

Phase 1

Phase 2

Gambar 5 Model Multi Channel - Multi Phase

Jaringan komputer adalah sejumlah komputer yang dikelompokkan dan dihubungkan satu dengan yang lainnya menggunakan protocol komunikasi melalui media transmisi atau media komunikasi, sehingga dapat saling berbagi data atau informasi, program - program, penggunaan bersama piranti keras (printer, hardisk, scanner, CD Room, serta piranti keras lainnya), dan memberikan layanan komunikasi antar pemakai.

RANCANG BANGUN PROTOTYPE DISPLAY ANTRIAN PELANGGAN DENGAN PENGGUNAAN TEKS DAN SUARA BERBASI JARINGAN INTRANET 
Agar dapat mencapai tujuan yang sama, setiap bagian dari jaringan komputer meminta dan memberikan layanan (service). Pihak yang meminta layanan disebut klien (client) dan yang memberikan layanan disebut pelayan (server). Arsitektur ini disebut dengan sistem client - server, dan digunakan pada hampir seluruh aplikasi jaringan komputer. Dalam suatu sistem jaringan, dimana seluruh komputer saling berbagi data dan resources satu sama lain sehingga tercapai efisiensi dalam pemanfaatan teknologi, amat dibutuhkan perangkat - perangkat khusus dan instalasi tertentu. Pada bab ini akan dijelaskan beberapa peralatan yang digunakan dalam sistem jaringan serta pengaturan TCP/IP pada sistem operasi Windows.

Jaringan komputer (Computer Network) adalah sekumpulan komputer yang dapat berkomunikasi satu sama lain, dapat menggunakan peralatan yang dapat diakses secara bersama - sama, dan dapat berhubungan dengan komputer induk sistem lain yang jauh jaraknya. Secara garis besar jaringan komputer menurut lingkup geografis dari radius jangkauannya dibedakan menjadi tiga (Tim Penelitian dan Pengembangan Wahana Komputer, 2003) yaitu :

Protokol Token di kembangkan oleh IBM pada pertengahan tahun 1980. Metode aksesnya melalui lewatnya sebuah token dalam sebuah lingkaran seperti cincin. Dalam lingkaran token, komputer komputer dihubungkan satu dengan yang lainnya seperti sebuah cincin. Sebuah sinyal token bergerak berputar dalam sebuah lingkaran (cincin) dalam sebuah jaringan dan bergerak dari sebuah komputermenuju ke komputer berikutnya, jika pada persinggahan di salah satu komputer ternyata ada data yang ingin ditransmisikan, token akan mengangkutnya ke tempat dimana data itu ingin ditujukan, token bergerak terus untuk saling mengkoneksikan diantara masing - masing komputer. (I Wayan Kardiasa, 2008).

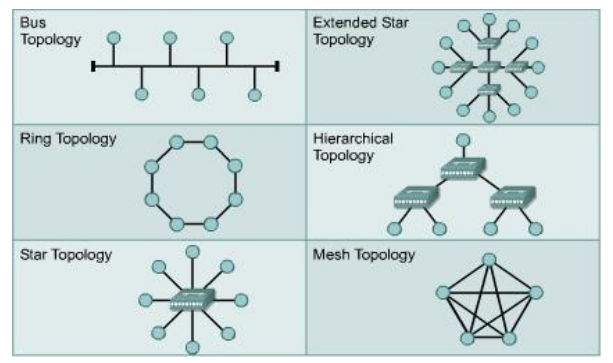

Gambar 6 Macam Topologi

Ada banyak media yang digunakan untuk membuat suatu jaringan komputer, pada dasarnya dibagi menjadi 2 macam yaitu kabel dan nirkabel. Terdapat beberapa macam teknologi pada masing - masing media ini. Media kabel merupakan media transmisi yang menyediakan saluran satu perangkat ke perangkat lainnya. Media transmisi adalah suatu jalur antara pemancar dan penerima dalam sistem transmisi data. Pada media guided terdapat tiga jenis kabel, yaitu :

1. Twisted Pair (Kabel Berpasangan)

Twisted pair merupakan medium yang paling murah dan banyak digunakan dalam transmisi guided. Twisted pair terdiri dari dua kabel tembaga yang terisolasi yang disusun dalam jalinan berbentuk spiral. Twisted pair dibagi menjadi dua jenis :

a. Unshielded Twisted Pair (UTP)

Kabel UTP digunakan untuk kabel telepon, bahkan lebih banyak lagi digunakan dalam gedung perkantoran sebagai medium untuk Local Area Network karena jauh lebih murah, dan lebih mudah digunakan dan dipasang. (www.aagusku.blogspot.com)

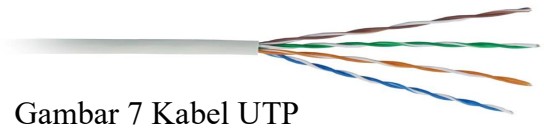

b. Shielded Twisted Pair (STP)

Kabel STP memiliki kualitas yang lebih baik sehingga harganya jauh lebih mahal dan lebih sulit penggunaannya dibandingkan dengan UTP (Lukas, 2006, p.58) (www.s3ntani.wordpress.com).

JURNAL ILMIAH TEKNIK MESIN, ELEKTRO DAN KOMPUTER Vol.1, No.3, November 2021, pp. 34 - 44 
2. Kabel Coaxial

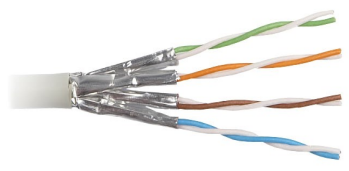

Gambar 8 Kabel STP

Kabel coaxial terdiri dari dua konduktor yang dapat digunakan untuk frekuensi yang lebih tinggi. Kabel ini terdiri dari konduktor berbentuk silinder untuk lapisan luar, yang mengelilingi konduktor bagian dalam. Kabel coaxial dapat digunakan untuk jarak yang lebih jauh dan dalam jaringan komunikasi yang lebih luas dengan stasiun dan jalur komunikasi yang lebih banyak (Lukas, 2006, p.61) (www.rhichiemalone.blogspot.com).

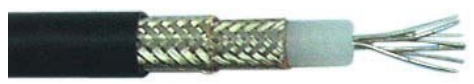

3. $\quad$ Fiber Optic (FO)

Gambar 9 Kabel Coaxial

Kabel ini menggunakan serat kaca atau plastik untuk mentransfer data dalam bentuk gelombang cahaya. Kabel fiber optic tidak terpengaruh oleh aliran listrik ataupun media magnet, kecepatan tinggi, dan dapat mencapai jarak yang jauh tanpa kehilangan data. (www.global-b2b-network.com).

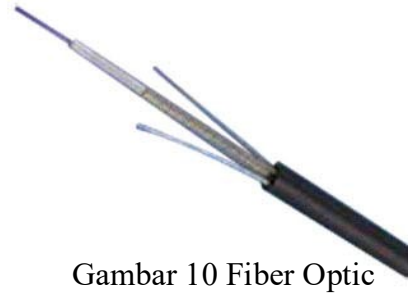

Jaringan client - server adalah memanfaatkan sebuah komputer dari jaringan sebagai central (pusat) pertemuan antar beberapa client pada aplikasi yang sama. Dalam proses pertemuannya tiap tiap client haruslah melakukan koneksi dengan server agar dapat bergabung pada aplikasi yang sama, proses inilah yang disebut dengan protokol komunikasi client - server (A.S. Tanenbaum, 1996). Proses protokol komunikasi jaringan client - server terlihat pada gambar dibawah ini.

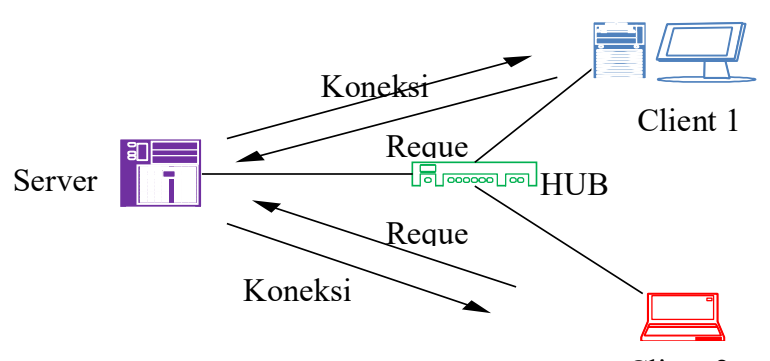

Client 2

Gambar 11 Jaringan Berbasis Client - Server

Jaringan berbasis server atau client - server dapat juga diartikan dengan adanya server didalam sebuah jaringan yang menyediakan mekanisme pengamanan dan pengelolaan jaringan tersebut. Jaringan ini terdiri dari banyak client dari satu atau lebih server. Client juga biasa disebut front - end meminta layanan seperti penyimpanan dan pencetakan data ke printer jaringan, sedangkan server yang sering disebut back end menyampaikan permintaan tersebut ke tujuan yang tepat.

Pada Windows NT, Windows 2000, dan Windows Server 2003, jaringan berbasis server diorganisasikan di dalam domain - domain. Domain adalah koleksi jaringan dan client yang saling berbagi informasi. Keamanan domain dan perizinan log on dikendalikan oleh server khusus yang disebut domain RANCANG BANGUN PROTOTYPE DISPLAY ANTRIAN PELANGGAN DENGAN PENGGUNAAN TEKS DAN SUARA BERBASI JARINGAN INTRANET 
*Dewi Amirakhima dkk / Jurnal Ilmiah Teknik Mesin, Elektro dan Komputer Vol 1. No. 3 (2021) 34 - 44

controller. Terdapat satu pengendali domain utama atau Primary Domain Controller (PDC) dan beberapa domain controller pendukung atau backup Domain Controller (BDC) yang membantu PDC pada waktu waktu sibuk atau pada saat PDC tidak berfungsi karena alasan tertentu.

Primary Domain Controller juga diterapkan di dalam jaringan yang menggunakan server Linux. Software yang cukup andal menangani masalah ini adalah sama yang sekaligus dapat digunakan sebagai penyedia layanan file dan print yang membuat komputer Windows dapat mengakses file - file di mesin Linux dan begitu pula sebaliknya. (http://www.nurwajianto.tk)

\section{Hasil dan Pembahasan}

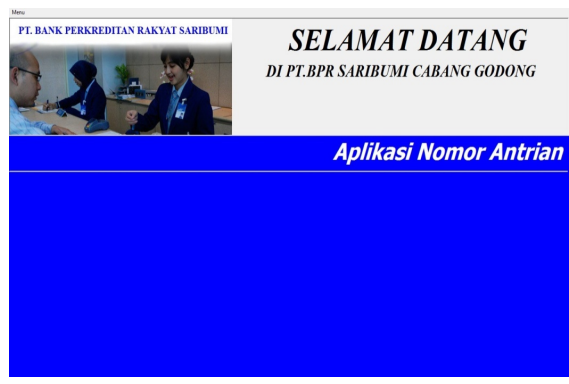

Gambar 12 Form Utama

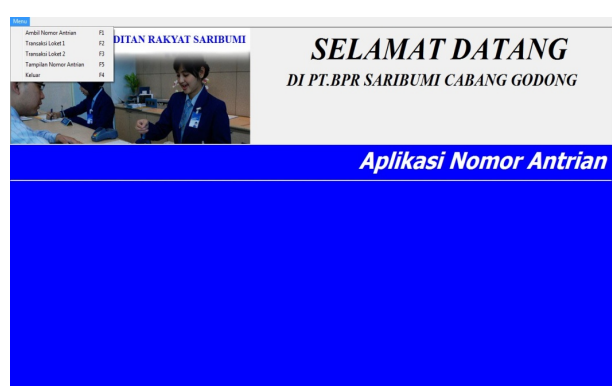

Gambar 13 Pilihan Form dari Form Utama

Fungsi : Sebagai form master Cara Kerja

(1) Pada sisi atas sebelah kanan terdapat pilihan menu

(2) Klik pada menu untuk menampilkan Ambil Nomor Antrian, Transaksi Loket

1, Transaksi Loket

2, Tampilan Nomor Antrian, Laporan Nasabah, Laporan Per User dan Periodik, Data User dan Keluar.

c. Perancangan Form Pada Server

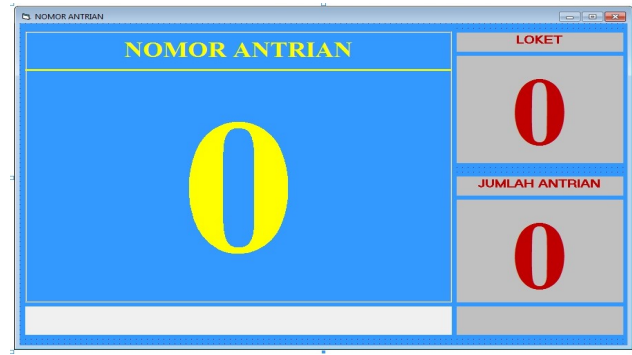

Gambar 14 Form Server

Fungsi : Untuk menampilkan nomor urut antrian

Cara kerja :

a. Tampilan nomor urut antrian ini akan berjalan jika counter number dijalankan.

b. Apabila counter number dijalankan maka akan muncul angka pada jumlah antrian.

c. Tampilan ini juga bisa berjalan jika teller menjalankannya aplikasi pada form teller.

d. Apabila teller menjalankan aplikasinya maka akan muncul angka pada nomor urut dan loket.

e. Perancangan Form Pada Teller 1 


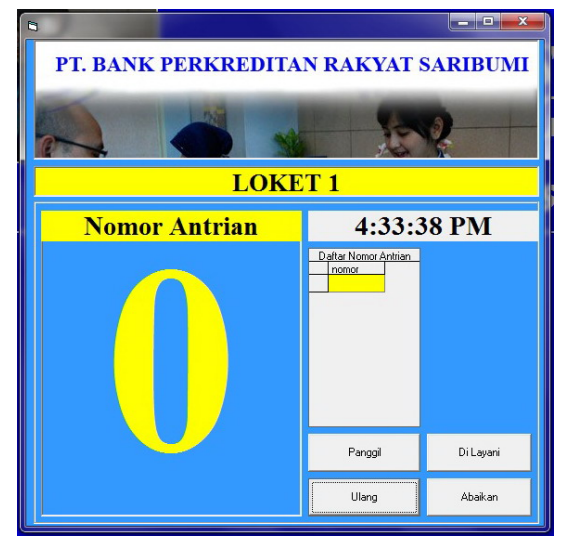

Gambar 15 Form Teller 1

a. Fungsi : Untuk menjalankan sistem aplikasi antrian

b. Cara kerja :

a. Pilih tombol panggil untuk memanggil nomor urut antrian.

b. Pilih tombol ulang untuk mengulangi atau memanggil ulang nomor antrian.

c. Pada tabel Daftar Nomor Antrian berfungsi untuk memudahkan seorang teller untuk mengetahui nomor antrian yang akan dipanggil.

f. Perancangan Form Pada Teller 2

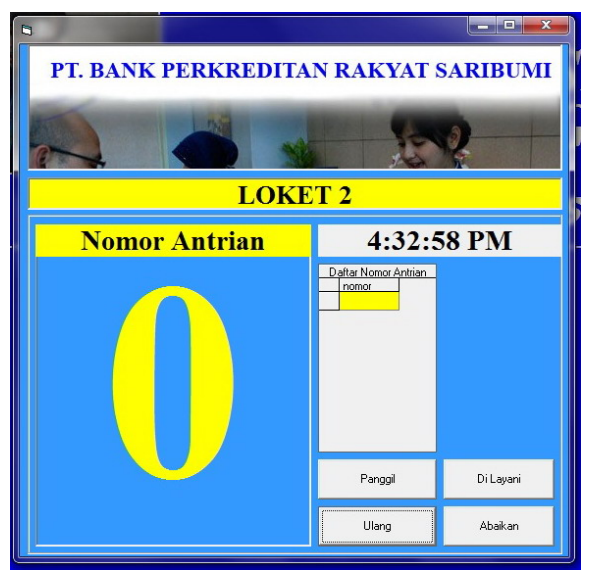

Gambar 15 Form Teller 2

Fungsi : Untuk menjalankan sistem aplikasi antrian

Cara kerja :

a. Pilih tombol panggil untuk memanggil nomor urut antrian.

b. Pilih tombol ulang untuk mengulangi atau memanggil ulang nomor antrian.

c. Pada tabel Daftar Nomor Antrian berfungsi untuk memudahkan seorang teller untuk mengetahui nomor antrian yang akan dipanggil

\section{Kesimpulan}

Dari uraian pembahasan diatas mengenai sistem aplikasi antrian loket dengan berbasis jaringan pada bank tersebut yaitu Kantor PT. BPR Saribumi Cabang Godong dapat disimpulkan bahwa :

a) Banyaknya terjadi kesalahan ke dalam database antrian saat pertama aplikasi antrian ini dijalankan.

b) Aplikasi ini dirancang dengan sistem jaringan LAN yang berbasis client - server dan banyak mengalami disconect antar komputer sehingga tidak dapat mengakses ke server.

RANCANG BANGUN PROTOTYPE DISPLAY ANTRIAN PELANGGAN DENGAN PENGGUNAAN TEKS DAN SUARA BERBASI JARINGAN INTRANET 
*Dewi Amirakhima dkk / Jurnal Ilmiah Teknik Mesin, Elektro dan Komputer Vol 1. No. 3 (2021) 34 - 44

c) Aplikasi ini dirancang hanya pada jaringan LAN (Local Area Network). Aplikasi ini dapat berjalan pada bandwith yang cukup rendah yaitu $10 \mathrm{kbps}$, sehingga apabila terjadi traffic yang cukup tinggi sekalipun prototype ini dapat berjalan dengan baik.

\section{Daftar Pustaka}

1. A.S. Tanenbaum, 1996; "Computer Networks 3rd Edition", USA : Prentice Hall Inc, NJ.

2. Biography penulis, Nurwajianto menamatkan pendidikan Sekolah Teknologi Menengah (http://www.nurwajianto.tk).

3. Guojun Lu, 1996; "Communication and Computing for Distributed Multimedia Systems", USA : Artech House Inc., Norwood, MA.

4. I Wayan Kardiasa, 2008; “Topologi Jaringan”, Nusa Dua Selatan (http://kardiasa.wordpress.com/topologi-jaringan/)

5. Kakiay, Thomas J, 2004; "Dasar Teori Antrian Untuk Kehidupan Nyata", Yogyakarta : Andi.

6. Kurose and Ross, 2004; "Computer Networking: A top-down approach featuring the Internet", 3rd edition, Addison Wesley.

7. Mulyono, S, 1991; “ Operations Research”, Jakarta : FE-UI.

8. Schroeder, Roger G, 1997; "Operations Management. McGraw - Hill Inc”. New Jersey.

9. Setiawan, Sandi, 1991; "Simulasi", Yogyakarta : ANDI OFFSET.

10. Siagian, P, 1987; "Penelitian Operasional : Teori dan Praktek", Jakarta : Universitas Indonesia Press.

11. Subagyo, Pangestu, dkk, 2000; "Dasar - Dasar Operations Research”, Yogyakarta : BPFE. 